\title{
El agroturismo como estrategia de dinamización económica local para el Cantón Déleg. (c) (1)(9)
}

\author{
Agrotourism as a local economic revitalization strategy for the Déleg Canton.
}

Norma Catalina Cobos Izquierdo. ${ }^{1}$, Yonimiler Castillo Ortega. ${ }^{2} \&$ Daniele Covri Rivera. ${ }^{3}$

Recibido: 06-01-2021 / Revisado: 11-01-2021 /Aceptado: 05-02-2021/ Publicado: 05-03-2021

\begin{abstract}
DOI: https://doi.org/10.33262/concienciadigital.v4i1.2.1579
\end{abstract}
Introduction. Tourism has become an important factor in the socioeconomic development of countries, as a consequence of the fact that local, endogenous and regional development is considered among the strategies that allow the progress of a territory, be it a locality or region. The globalization process, the increasing decentralization of public policies and the retraction of the State have contributed to this result, which had among its functions to provide basic services to the population in order to promote a better quality of life. Objective. Design an agrotourism development plan as a local economic revitalization strategy for the Déleg Canton. Methodology. The research design was non-experimental, descriptive, with a mixed approach, where the chosen population was fifty (50) residents of the Déleg Canton. Results. In this sense, it is evident that $74 \%$ of the population consulted, specified that the tourist attractions of that area are not given adequate treatment to generate agrotourism in the area, they indicate that the main source of income in this community is given by agriculture. Conclusion. It was concluded that the formation of tourist routes is a great opportunity in places where there are potentially tourist resources, which are not used or are promoted in isolation, constituting an option for endogenous local / regional development.

\footnotetext{
1 Universidad Católica de Cuenca, Posgrado, Maestría en Desarrollo Local Mención en Ordenamiento Territorial, Cuenca, Ecuador. norma.cobos@est.ucacue.edu.ec, https://orcid.org/0000-0002-7667-0444

2 Universidad Católica de Cuenca, Posgrado, Maestría en Desarrollo Local Mención en Ordenamiento Territorial, Cuenca, Ecuador, ycastilloo@ucacue.edu.ec, https://orcid.org/0000-0002-7710-5199

3 Universidad Católica de Cuenca, Carrera de Economía, Cuenca Ecuador, daniele.covri@ucaue.edu.ec, https:orcid.org/0000-0002-2495-0399
} 
Keywords: Agrotourism, Strategy, Economy, Local Development.

\section{Resumen.}

Introducción. El turismo se ha convertido en un importante factor de desarrollo socioeconómico de los países, como consecuencia de que el desarrollo local, endógeno y regional, se considera entre las estrategias que permiten el progreso de un territorio, ya sea una localidad o región. A este resultado han contribuido el proceso de globalización, la creciente descentralización de las políticas públicas y la retracción del Estado, que tenía entre sus funciones brindar servicios básicos a la población a fin de propiciar una mejor calidad de vida. Objetivo. Diseñar un plan de desarrollo de agroturismo como estrategia de dinamización económica local para el Cantón Déleg. Metodología. El diseño de la investigación fue no experimental, de corte descriptivo, con un enfoque tipo mixto, donde la población escogida fue de cincuenta (50) pobladores del Cantón Déleg. Resultados. En este sentido, se evidencia que el $74 \%$ de la población consultada, especifico que a los atractivos turísticos de esa zona no se les otorga un tratamiento adecuado para generar el agroturismo en la zona, ellos indican que la fuente principal de ingreso en esta comunidad viene dada por la agricultura. Conclusión. Se concluyó que la conformación de rutas turísticas resulta una gran oportunidad en lugares donde existen recursos agrarios que constituyen una opción de desarrollo local/regional endógeno.

Palabras claves: Agroturismo, Estrategia, Economía, Desarrollo Local.

\section{Introducción.}

El turismo es una actividad que abarca la economía, la sociedad y la naturaleza. En los últimos tiempos, se han desarrollado muchas formas diferentes de actividades y productos turísticos que están ganando terreno en términos de demanda. Entre tales se presentan, el agroturismo, el turismo ecológico y el turismo rural. La presente investigación apoya el análisis del agroturismo desde un enfoque de desarrollo local en el cantón Déleg. Esta modalidad del turismo se presenta en Europa a finales de los años sesenta, aunque de forma efímera, pues solo abarcaba el alojamiento del visitante, sin una vinculación directa con el trabajo en el campo. Dentro de las preguntas científicas de investigación a las que se quiere dar respuesta están: ¿Cuáles son los referentes teóricos sobre el desarrollo turístico local y la planificación del agroturismo en el Cantón Déleg?, ¿Cuál es la situación actual del turismo dentro de la perspectiva económica del cantón Déleg? y ¿Cuáles son los componentes de un plan de desarrollo de agroturismo para el cantón Déleg?

En lo que se refiere a los primeros avistamientos del agroturismo en el mundo se dan en las zonas montañosas de Alemania. Asimismo, comenzando la década de 1960, se propaga por 
el resto de los países integrantes del viejo continente, con mayor fuerza en Bélgica, Países Bajos, Holanda, Francia e Italia, sumando agricultores y visitantes motivados por este tipo de producto turístico (Velasco \& Cerro, 2014). En la actualidad el mercado europeo es el mayor consumidor de esta modalidad de recreación y esparcimiento sano. De esta forma el agroturismo contribuye con un alto valor agregado en las relaciones igualitarias, consideradas por las buenas prácticas, tradiciones y sabiduría de las zonas rurales. A su vez, se convierte en un espacio de sostenibilidad para la agricultura en varias naciones (Alonso, 2019). En América Latina el agroturismo comienza a dar sus primeros pasos a inicios del año 2000. En este sentido los países con más desarrollo son Chile, Argentina, Colombia, Perú y Costa Rica.

Este último destino ubicado en Centroamérica desarrolla tres alternativas de agroturismo, en cooperativas, pequeños ganaderos y el turismo comunitario organizado por indígenas y campesinos asociados. Por otro lado, Argentina es el segundo país en la región que resalta en esta práctica de agroturismo, siendo atractivo en el cultivo de uvas para la producción de vinos y la producción ganadera, atracciones para los visitantes que prefieren este tipo de actividades agrícolas. Sumado a lo anterior, en otras regiones del país lo llamativo son las actividades de la pesca (Roig, 2014).

Por su parte, Ecuador es un país rezagado en este tipo de actividad turística, sin embargo, a través del Ministerio de Turismo busca impulsar el agroturismo en varias zonas del país. En este sentido se implementa el Plan Nacional para el Agroturismo, mismo que pretende consolidar estrategias para el desarrollo de esta actividad. El objetivo central de esta propuesta gubernamental es brindar un servicio de calidad e innovador con una infraestructura sólida capaz de competir en la región, haciendo atractivo los destinos ecuatorianos. El país cuenta con múltiples escenarios geográficos, diversidad en el clima e hidrografía que sustentan las diversas actividades agrícolas, convirtiéndose en fuertes atractivos turísticos (Ministerio de Turismo, 2020).

La importancia del fortalecimiento de este tipo de producto puede generar grandes beneficios a nivel nacional, cuando se aprecia que el sector turístico aportó el 1.61\% al PIB nacional en el año 2016, generados por 1.5 millones de visitantes que aportaron alrededor de 1551 millones de dólares. En este propio año la provincia de Cañar, donde se ubica el cantón Déleg, aportó con un Valor Agregado Bruto del 0.85\%, siendo este poco significativo, pero a la vez sobresaliente entre otras regiones del país (CFN, 2017). El cantón Déleg cuenta con varios atractivos turísticos entre los que destacan la meseta del Pachamama, Laguna de Guabizhung y Laguna de Jacarin. Además, sobresalen las tradiciones, su cultura, la gastronomía, las fiestas y danzas. No obstante, el cantón no cuenta con un programa de desarrollo de agroturismo que explote las posibilidades de desarrollo parroquial y cantonal (GAD Déleg, 2020). 
Entre las principales actividades agrícolas resalta el cultivo de tomate de árbol, aguacate, chirimoya y manzana chilena. Pero la oportunidad puede ser perfecta para rescatar el cultivo de otras frutas como manzanas, peras, duraznos y capulí, abandonadas por campesinos de la zona, en mayor medida por la afectación de otras plantas que cubren estos sembrados. Asimismo, es tradición de la zona que algunas familias siembren plantas medicinales a pocos metros de los hogares, entre las cuales se encuentran el toronjil, manzanilla, menta, violeta, hierba luisa, fucsia y amaranto. Por otro lado, son frecuentes los cultivos de maíz con fréjol, habas y en menor medida arveja y papa (GAD Déleg, 2020). Algunos de los problemas que sobresalen negativamente en el Cantón Déleg, según Jaime et al (Jaimes, 2016) son los siguientes:

- El poco tiempo para el disfrute de vacaciones y paseos;

- Escasa capacitación en la comunidad;

- Deficiente aprendizaje personal para ejercer un trabajo adecuado;

- Deficiente control policial de la delincuencia;

- Muy poca demanda de trabajo remunerado;

— Escasa comercialización de la producción agropecuaria y artesanal;

- Escasa participación de las comunidades en actividades socio ambientales;

- Baja frecuencia en el control social de la delincuencia;

- Desaparición de especies de flora y fauna en la comunidad;

— Poca atención de los reclamos, demandas o requerimientos sociales.

Dentro de este contexto, y luego de la problemática planteada, esta investigación tiene como objetivo central diseñar un plan de desarrollo de agroturismo como estrategia de dinamización económica local para el Cantón Déleg., para lo cual se establecen los siguientes objetivos específicos: 1.- Analizar los referentes teóricos sobre el desarrollo turístico local y la planificación del agroturismo, 2.- Diagnosticar la situación actual del turismo dentro de la perspectiva económica del cantón Déleg. 3.- Estructurar los componentes de un plan de desarrollo de agroturismo para el cantón Déleg. 4.- Validar el plan de desarrollo de agroturismo mediante el criterio de expertos. La investigación se realizará desde un enfoque cualitativo, ya que se emplea la observación participante para constatar cuales son los proyectos turísticos que se ejecutan en la actualidad y su alcance y conocer de primera mano el contexto o situación del cantón Déleg en cuanto a su infraestructura y condiciones potenciales de este territorio.

\section{Marco Teórico}

Desde hace miles de años los seres humanos han sentido la necesidad de desplazarse de un sitio a otro por el simple hecho de conocer nuevos lugares y poder guardarlos en su memoria como experiencias gratas e inolvidables de su vida. La recreación y el esparcimiento se puede 
evidenciar desde la antigua Grecia y el estilo de vida de sus habitantes. Estos le prestaban gran atención a la diversión, la cultura, la religión y los deportes, de ahí que sean los creadores de los actuales Juegos Olímpicos que se efectúan cada cuatro años en la actualidad. Actividades que provocaban el movimiento de grandes cantidades de personas por sus territorios (Anago \& Rodriguez, 2013)

Respecto a la historia de la humanidad, el turismo como manifestación sociocultural es de origen relativamente reciente (Gurria, 2004). Sin embargo, para comprender su desarrollo, rápida expansión y fortaleza, es importante abordar sus antecedentes más remotos. El turismo ha evolucionada a lo largo de la historia del hombre, de allí que se ha diversificado las razones por las cuales se realiza el turismo, así como los medios y sistemas de los cuales el turismo se ha valido para su realización. Al igual que la industria y el comercio, el turismo ha impulsado y a su vez ha sido impulsado, por el desarrollo de medios de transporte y vías de comunicación (Cárdenas, 2001).

Considerando la amplitud y flexibilidad del turismo, Gurría (2004) afirma que el mismo es tan antiguo como el hombre y equipara los movimientos migratorios de la cultura nómada con la idea del hombre viajero o móvil, dada por la presencia continua de visitantes y de localidades receptoras. El hombre primitivo se desplazaba constantemente por cambios climáticos en busca de alimentos y vestido; luego al domesticar animales y sembrar la tierra, se desplazaba por necesidades de pastoreo y de intercambio de excedentes. Para este autor, surgieron así los primeros viajes de negocios, aunque dichos desplazamientos no eran de carácter temporal o en la búsqueda del descanso, sino por razones de supervivencia. Siglos después los griegos y romanos comenzaron a desplazarse hacia aguas termales y medicinales para recuperar la salud deteriorada por las guerras. Luego, durante la edad media surgieron los motivos religiosos, pues los cristianos e islámicos creían ganar favores de seres supremos al visitar lugares santos (peregrinaciones).

Según Acerenza (2001), en la antigua Babilonia existieron claras evidencias de viajes, por fiestas religiosas y competencias atléticas hacia las ciudades de Atenas, Delfos, Corinto y Olimpia. En época del Imperio Romano existían itinerarios y guías en los que se mencionaban rutas, nombres de caminos, duración de viajes y distancias. En las Guerras Santas, las cruzadas mantuvieron un constante fluir de viajeros armados por diversos caminos y lugares, por lo que el comercio y los desplazamientos turísticos fueron eventualmente consecuencias no esperadas. También los misioneros expandiendo el cristianismo viajaron por todo el mundo. Según Ramírez (2006), posteriormente en el Renacimiento, Marco Polo fue uno de los primeros turistas y su primer viaje lo hizo de Venecia a la China regresando con pieles y esencias; al regresar escribió el primer libro conocido sobre turismo: "Los Viajes de Marco Polo". 
Un poco más adelante en la historia, en la edad media se llevan a cabo grandes desplazamientos de individuos por las crecientes manifestaciones religiosas que afloraron en esta época. Por otro lado, en la era moderna, se hizo costumbre entre los ingleses, enviar a sus hijos recién graduados en un viaje que duraba de entre tres y cinco años aproximadamente, por algunos países de Europa. Luego, entre los siglos XVII y XIX ocurren profundos cambios que van a revolucionar el estilo de vida existente en aquel momento. Se evidencia la revolución científica e industrial, convirtiendo al turismo en el primer beneficiado directo en los últimos años del siglo XX (Anago \& Rodriguez, 2013).

Otro viajero histórico fue Cristóbal Colón, quien con su afán de desplazarse hacia oriente descubrió por accidente a la América; luego aparecieron los conquistadores, quienes en busca de riqueza y poder adicionaban a sus imperios las recientes tierras descubiertas y sus habitantes. Luego para conocer las nuevas culturas y civilizaciones, en los siglos XVII y XVIII, los hijos de los nobles o alta burguesía, viajaban por 2 o 3 años por razones de educación y se incluían también actividades de recreación; luego éstos con sus conocimientos en métodos y técnicas agrícolas, de intercambio y rutas, ejercían como diplomáticos (Gurría, 2004).

Con el desarrollo de las nuevas formas de viajar a través del mundo a mediados del siglo XIX el turismo se convirtió en un negocio aún más grande. Así, en el siglo XX a medida que los viajes aéreos fueron progresivamente desregulados y desacoplados de los transportistas vanguardistas, su desarrollo ha ido en aumento. Según (Muñoz \& Requena, 2006): “el turismo es uno de las pocas actividades humanas que ha sido abordada desde diversas disciplinas (economía, ecología, psicología, geografía, sociología, historia, estadística, derecho y las ciencias políticas y administrativas)" (p. 141).

Por otro lado, la Organización Mundial del Turismo (OMT, 2020) (p.86) define:

El turismo es un fenómeno social, cultural y económico que supone el desplazamiento de personas a países o lugares fuera de su entorno habitual por motivos personales, profesionales o de negocios. Esas personas se denominan viajeros (que pueden ser o bien turistas o excursionistas; residentes o no residentes) y el turismo abarca sus actividades, algunas de las cuales suponen un gasto turístico.

\section{El turismo como estrategia de desarrollo local}

El turismo ejerce gran influencia en el desarrollo local de un territorio. Sumado a lo anterior, algunas medidas gubernamentales pueden aportar con una mejor infraestructura de servicios básicos, aportando así, a una mejor calidad de vida de los habitantes de la zona y a los visitantes, denominados turistas. Si después de un análisis superficial se determina que las condiciones no están aptas para asumir nuevos desafíos que eleven el número de visitantes a 
determinado sitio, se hace necesario elaborar estrategias que reviertan la situación actual y de esta forma aportar al mejoramiento de la economía sectorial y nacional (Gambarota \& Lorda, 2017).

Barrera (2009) define el agroturismo como una particularidad del turismo rural, con la diferencia de que este parte de la producción agrícola, asociado a la cultura y la historia del lugar donde se desarrollan las actividades. Chryssoula et al (2009) realizaron un estudio sobre negocios de agroturismo en la isla de Lesbos y Florina, Grecia, especialmente para comprender la relación entre la satisfacción completa del cliente y la repetición de su visita. Siguieron la teoría de que la calidad del servicio por sí sola no necesariamente alienta a los clientes a repetir sus elecciones, sino que es necesaria una satisfacción completa de los mismos.

\section{Características del agroturismo}

Según Arrieta (2006) las características del agroturismo son:

- Es una de las modalidades del turismo rural.

- Se caracteriza porque el visitante participa activamente de las actividades productivas.

- La familia del productor agrario participa en la atención de los turistas.

- El atractivo de un predio dedicado al agroturismo crece proporcionalmente a la diversificación del mismo.

- Es recomendable que los productores incorporen la mayor cantidad de atractivos posibles, aunque estos puedan tener solo una finalidad demostrativa y no productiva.

El Instituto Interamericano de Cooperación para la Agricultura con sede en Costa Rica, plantea la siguiente fórmula para una correcta planificación de un programa de agroturismo.

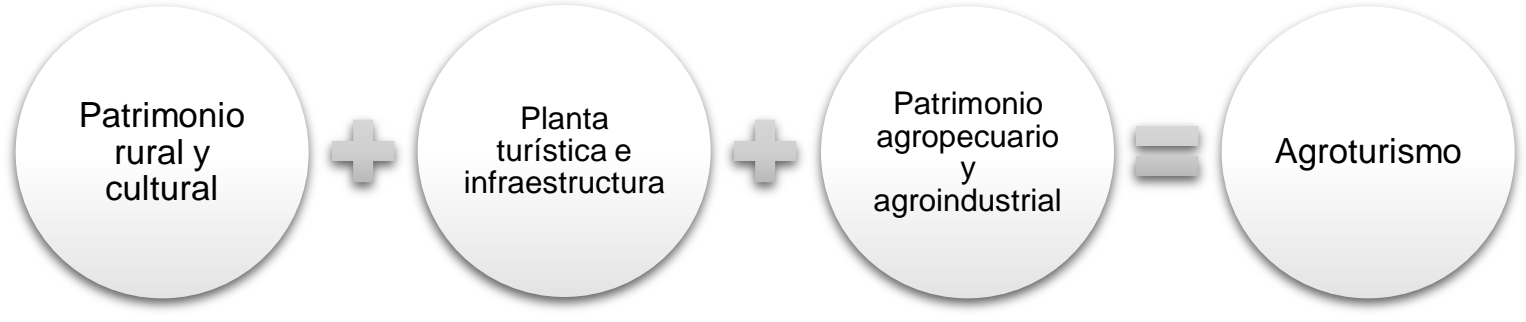

Figura 1. Planificación para el desarrollo del agroturismo

Fuente: (IICA, 2000)

Como se puede apreciar es fundamental cumplir con cada uno de los requisitos anteriores antes de emprender o proponer un plan de desarrollo para la aplicación del agroturismo en cualquier territorio rural. Por tanto, cada fase o pasos a seguir deben ser estudiados minuciosamente. 


\section{Metodologia.}

En el desarrollo de la investigación se utilizaron métodos teóricos: el método inductivo y deductivo, método analítico y sintético. El método deductivo permitió establecer las peculiaridades de una situación específica que se estudia por el origen o resultado de atributos o declaraciones contenidas en propuestas o leyes científicas de carácter general manifestadas anteriormente. A través de la deducción emanan los efectos específicos o determinados de las conclusiones adoptadas o generales (Abreu, 2014). En este caso permitió comprender las generalidades teóricas en cuanto a la planificación del agroturismo, sus generalidades y características para poder hacer un juicio particular de este proceso del desarrollo.

El método inductivo, parte de situaciones y datos precisos para arribar a conclusiones o generalidades (Mora, 2011). Este permitió comprender a partir del razonamiento los casos particulares de aplicación del plan de desarrollo de agroturismo en el cantón Déleg para establecer aspectos específicos. El método analítico, profundizó el objeto de estudio, enfocándose en el análisis de la parte teórica de la investigación como lo es el desarrollo local, desarrollo turístico, desarrollo del agroturismo, estrategias de desarrollo. El método sintético, permitió integrar el análisis teórico que aborda el objeto de este estudio científico para la comprensión de la planificación del desarrollo del agroturismo, mediante el resumen de los componentes y sus directrices.

De los métodos empíricos, tradicionales para esta investigación científica, se utilizó la entrevista. La entrevista semiestructurada o mixta, que permitió recoger datos sobre los proyectos ejecutados, así como el fortalecimiento que generó los procesos de desarrollo en su territorio, esta entrevista, se le efectuó a sus principales actores como: presidentes de las juntas parroquiales, a los funcionarios públicos relacionados a temas de desarrollo rural y demás representantes locales relacionados con el tema de investigación, dentro de los elementos a considerar para la formulación de la estrategia para el desarrollo del plan agroturístico están: el ámbito o campo de actividad: dónde va a competir la empresa, las capacidades distintivas: con qué instrumentos va a competir la empresa, la ventaja competitiva: para qué compite la empresa, las sinergias: cómo va a competir la empresa.

Para el desarrollo de la investigación se aplicó un diseño de campo porque permitió la recolección de la información, directamente de los sujetos investigados, es decir de los habitantes del cantón Déleg. De igual manera, el presente estudio se apoyó en la investigación documental, porque se obtuvieron fuentes confiables que lograron la lectura y análisis bibliográfico, los cuales permitieron la recopilación de la información a través de fuentes oficiales, como, por ejemplo: revistas y artículos científicos. En relación al nivel de la investigación, se basó en un carácter descriptivo y exploratorio, por cuanto el estudio permitió recopilar y analizar datos de la situación del cantón Déleg. 
Para efectos de la ejecución objeto de estudio, se consideró un diseño no experimental, porque en el desarrollo del mismo no se manipularon las variables correspondientes al agroturismo y a la dinamización del desarrollo local, sino que se observaron cómo actúan y como se relacionan las mismas, para posteriormente analizarlas y llegar a una conclusión. Para el caso presente, la muestra estuvo conformada por cincuenta (50) personas, a quienes se les aplicó la encuesta, lo cual constituyó la población total y de quienes se obtuvo información confiable, esta población fue determinada dada la situación del COVID-19 y la pandemia que se estaba presentando donde los habitantes de este cantón estaban un poco desmotivados en querer responder la encuesta por el temor de contagiarse, sin embargo, se logró hacer el contacto de esa cantidad de consultados.

En cuanto a las técnicas de recolección de información, se consideró la encuesta, aplicando un cuestionario de preguntas con quince (15) ítems, donde se plantearon respuestas enmarcadas en una escala dicotómica y la escala de calificación de Likert. Para realizar el proceso de recopilación de la información y datos adquiridos se siguieron los siguientes pasos:

- Estudio crítico de la información; es decir limpieza de información defectuosa: discordante, inconclusa, no oportuna, etc.

- La información recopilada en la entrevista fue examinada y trasladada al documento.

- La información procedente de la encuesta se estudiará y se desplegará en una hoja de cálculo de Excel, para su posterior tabulación, diseño de tablas estadísticas y figuras respectivas.

- Las matrices del estudio realizado se recopilaron con la información aportada por la población del ámbito de estudio y por los expertos en el área.

- Luego de procesada la información y tabulado los datos, se procedió a la presentación y discusión de resultados donde se hizo una contrastación de lo obtenido con la teoría utilizada.

- Una vez contrastado los resultados y elaboradas las matrices, se formularon las fases del plan de desarrollo agroturístico en el Cantón Déleg, caracterizando cada una las actividades, programas y proyectos contentivos de la propuesta, mediante los métodos deductivos en base a los datos obtenidos.

- Luego de la formulación de la propuesta se realizó el envio del formato para la validación del plan de desarrollo con los expertos correspondientes, mediante la una matriz donde se especifican los criterios del plan, la cual fue enviada por correo electrónico, para que respondieran en línea si para su criterio se cumple o no con las fases.

\section{Discusión de resultados}

De acuerdo a la investigación realizada referente al desarrollo turístico local del cantón Déleg 
Barrera (2009) expone que el agroturismo tiene la particularidad de trabajar directamente con el territorio rural de las poblaciones, porque es allí donde nace la agricultura, que a su vez es acompañada de lugares, sitios, entre otros, que juntos pueden lograr el atractivo necesario para potenciar el desarrollo de una comunidad, en este mismo orden de ideas, el Instituto Interamericano de Cooperación para la Agricultura con sede en Costa Rica, plantea una fórmula para de manera correcta planificar un programa de desarrollo dirigido al agroturismo, donde hay que considerar el patrimonio rural y cultual, la infraestructura turística, el patrimonio agroindustrial y por último el agroturismo.

La información obtenida en este proyecto de investigación se hizo a través de encuestas personalizadas a los productores y/o dueños de las granjas agroturísticas, trabajadores que prestan sus servicios en dichas granjas y a personas involucradas con la actividad. Las personas estuvieron dispuestas a dar información para facilitar la investigación, colaborando con datos y experiencias que han obtenido a través de los años que han venido realizando su actividad laboral. Al realizar la recolección de datos y el procesamiento de la información con las encuestas dirigidas al universo del cual se basa este proyecto de investigación, se obtuvieron los siguientes resultados:

En primer lugar, se presenta la figura $\mathrm{N}^{\circ} 1$, se puede apreciar el conglomerado que refiere los ítems 1, 4, 5, y 7, donde se evidencian las respuestas emitidas por los entrevistados, los cuales fueron 50 en total, por ello, se tiene que la comunidad donde se desarrolla el estudio exponen que aun cuando existen atractivos turísticos en el Cantón Déleg, ellos desconocen el tema del agroturismo, esto expuesto por 46 de las personas consultadas, por lo tanto, al desconocer el termino de agroturismo, obviamente no conocen sus beneficios, y también la forma de como poder desarrollar el agroturismo, en esta zona, ellos aluden que en su mayoría, que si están de acuerdo en implementar estrategias para impulsar el desarrollo del mismo.

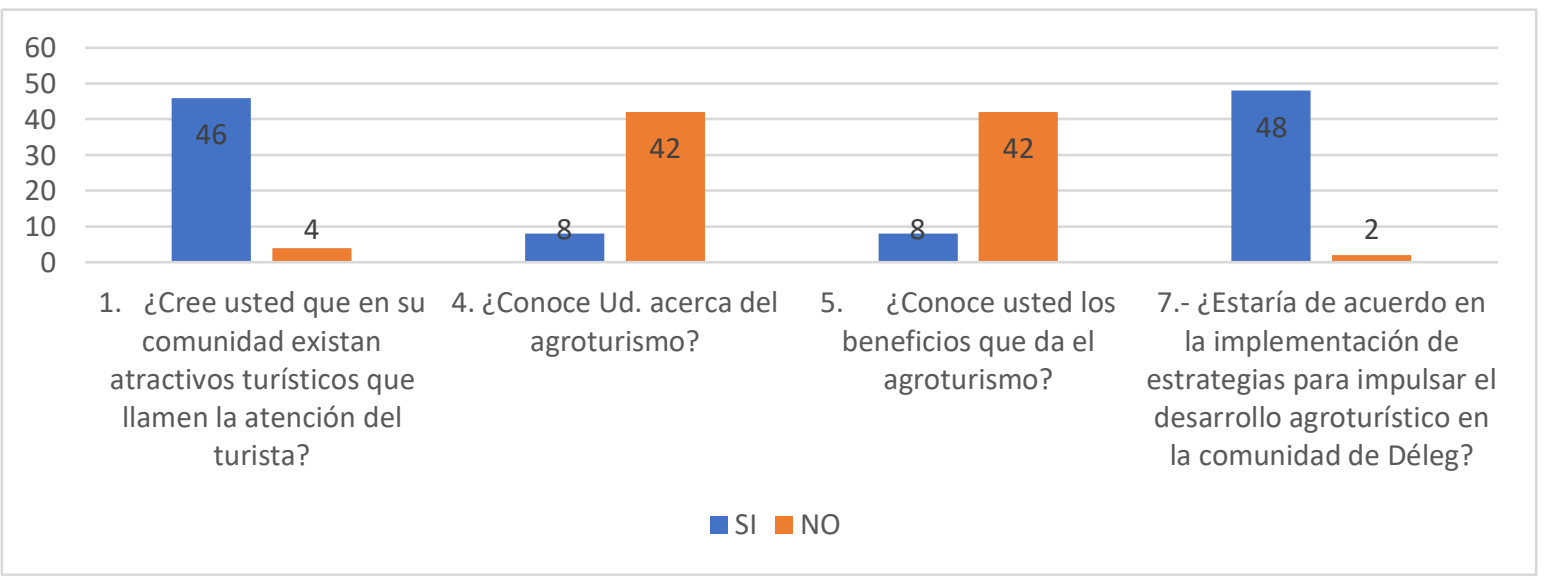

Figura 2. Respuestas emitidas por los consultados, ítems 1-4-5-7. Fuente: Elaboración propia. 
En este sentido, se presenta la figura 3, donde se evidencia que el $74 \%$ de la población consultada, especifico que a los atractivos turísticos de esa zona no se les otorga un tratamiento adecuado para generar el agroturismo en la zona, de igual forma, en la figura 4, ellos indican que la fuente principal de ingreso en esta comunidad viene dada por la agricultura.

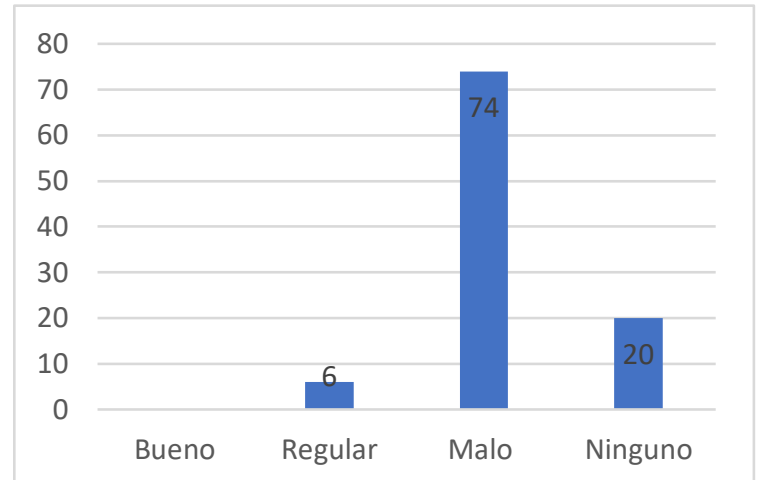

Figura 3. Manejo de los atractivos turístico. Fuente: Elaboración propia.

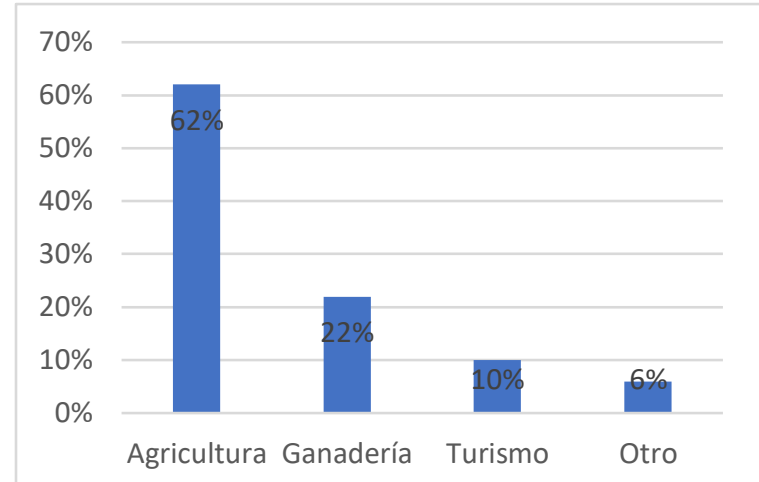

Figura 4. Principal fuente de ingreso. Fuente: Elaboración propia.

Desde este punto de vista, en la figura 5, se tiene que, en el Cantón Déleg, y según la entrevista realizada, sus habitantes muestran que carecen de capacitación agroturística en sus comunidades, sin embargo, los consultados como se muestra en la figura 6, ellos exponen que pueden participar en proyectos con estrategias diferentes, como por ejemplo, la de alimentación, es decir, ofreciendo sus mejores platos y comidas típicas de este cantón, que pueda ayudar a la promoción turísticas de sus comunidades.

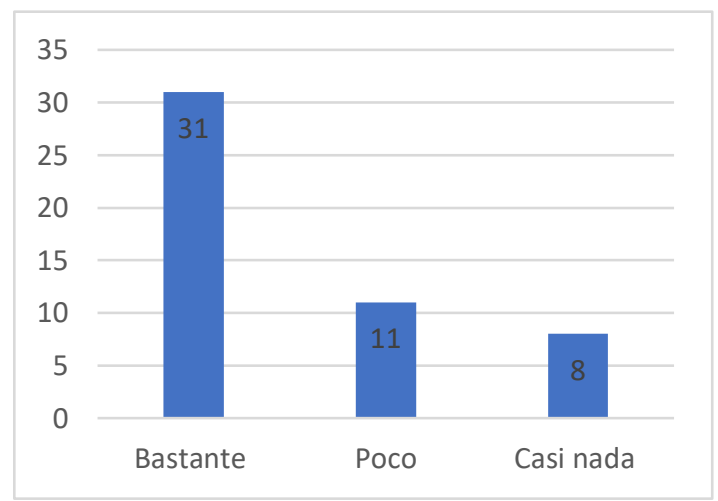

Figura 5. Falta de capacitación. Fuente: Elaboración propia.

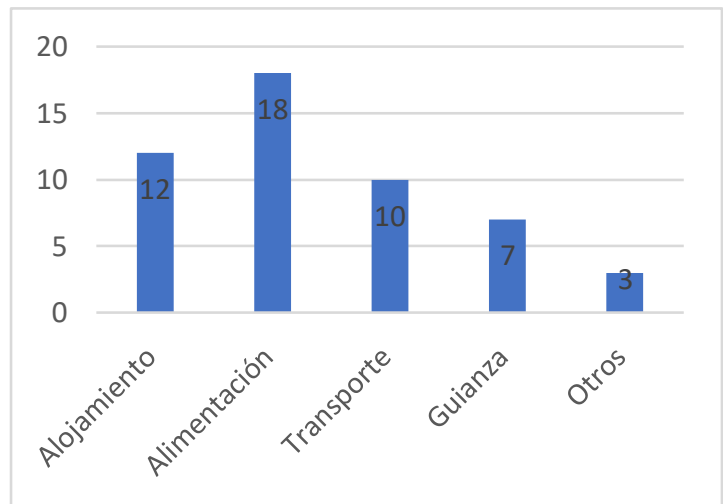

Figura 6. Estrategia de participación. Fuente: Elaboración propia.

En la figura 7 y 8 se puede evidenciar que el grado de importancia que se les otorga a la actividad turística es alta, solo que esta no es bien manejada, por lo tanto, los consultados consideran que dentro de los factores a mejorar en su mayoría están los que tienen que ver 
con la infraestructura, del mismo modo, la seguridad, la organización, la promoción, entre otros.

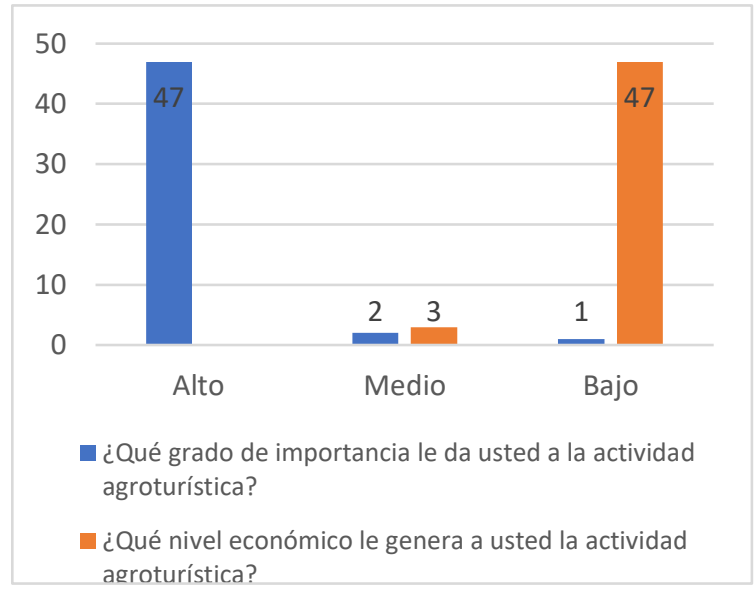

Figura 7. Importancia de la actividad turística Fuente: Elaboración propia.

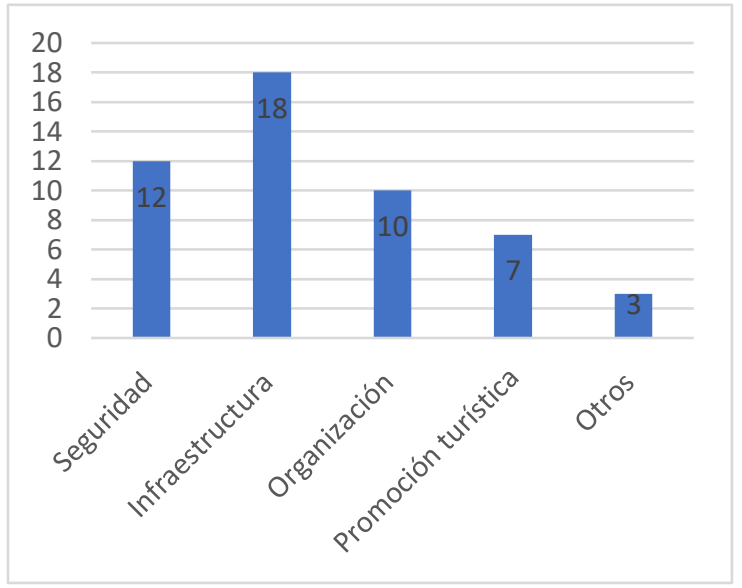

Figura 8. Factores a mejorar en el cantón Déleg. Fuente: Elaboración propia.

Es importante mencionar, que según el diagnóstico realizado sobre la situación actual del turismo dentro de la perspectiva económica del cantón Déleg, se procedió a elaborar una matriz DAFO que permitió tener una clara definición de las carencias y necesidades que afectan esta localidad, según como se evidencia en la tabla 1 referida a la matriz FODA del ámbito de estudio.

Con sus receptivos habitantes, el Cantón Déleg espera a sus visitantes con atractivos turísticos como: las lagunas de Surampalti y Guabizhún, el centro urbano, en donde se puede realizar actividades familiares y de recreación, tales como la caminata. Si el interés del visitante por la historia de este cantón es mayor, las ruinas arqueológicas de Pachamama es la fuente de consulta ideal. La Casa Cordero de Surampalti, el templete donde nació Luis Cordero, son lugares de este cantón, que el visitante debe visitar si se quiere sumergir en la amplia historia de Déleg.

No se puede dejar de mencionar la presencia de El Camino del Inca, declarado Patrimonio Mundial de la Humanidad por la Unesco en el año 2014, este lugar es reconocido por el ingenio vial y de control que el imperio Tahuantinsuyo manejaba desde Argentina, Chile, Bolivia, Perú, Ecuador y Colombia, en este sentido, la planta turística del cantón se encuentra en un nivel de desarrollo medio, existe considerable inversión local, los mismos que se encuentran brindando servicios turísticos.

Dentro del catastro registrado en el Municipio de Déleg de establecimientos de servicios del cantón que ejercen función hasta la actualidad se encuentran registrados en el sector hotelero 2 hoteles equipados con todos los servicios, cuya demanda en épocas festivas es alta, el resto 
del año la tasa de ocupación es concurrente; principalmente. Sin embargo, dentro de esta área existe un poco deficiencia en atención al cliente. Por otro lado, cuenta con un restaurante que brinda alimentación nacional e internacional, especializándose en platos tradicionales.

Se registra también 6 restaurantes de segunda y tercera categoría; el personal de los establecimientos de igual manera requiere previa capacitación en cuanto a la preparación y el expendio de alimentos y bebidas. Sin embargo, en la ciudad de Cañar se rescatan 7 hoteles, 1 hostal y 16 restaurantes, en la ciudad de El Tambo 2 hostales y 2 restaurantes, y en la Parroquia Ingapirca 1 Posada y14 restaurantes, que en resumen se definen de segunda y tercera categoría.

Desde este punto de vista, la infraestructura turística que ofrece el cantón están la ruta cultural-arqueológica de Cañar y Azuay que articula al complejo arqueológico de Ingapirca, al santuario de la Virgen del Roció de Biblián, al coloso Abuga, al santuario de San Francisco de Azogues, al Complejo Arqueológico de Cojitambo, al pueblo pintoresco de Déleg, la laguna de Guabizhun, al pueblo de Solano, las ruinas de Paccha Mama y a Pumapungo de la ciudad de Cuenca en la provincia del Azuay. A través de este recorrido es posible observar la elaboración de artesanías y degustar de la comida tradicional de la zona, que realizan sus habitantes.

Tabla 1

Matriz FODA

\section{FORTALEZAS}

Conocimiento de cultivo y cosecha de alimentos.

Existencia de alimentos nutritivos

F2 que son de gran atractivo para el visitante.

F3 Formación de grupos de trabajo.

Suministro de herramientas agrícolas

F4 para la siembra y cosecha de los alimentos.

F5

Atractivos turísticos únicos en el país.

Planta turística: posee atractivos que han sido reconocidos por el MITUR como

F6 Patrimonio Cultural del Ecuador el Camino del Inca, declarado Patrimonio Mundial de la Humanidad por la Unesco en el año 2014.

DEBILIDADES

\section{OPORTUNIDADES}

Modificación de la manera de consumir los alimentos por parte de los turistas.

Turismo de relevancia al recorrer $\mathbf{O 2}$ grandes pastizales y siembras de diversos alimentos, sector primario clave para la economía del país.

Margen de distancia entre los

O3 agricultores de la zona para la equidad en la siembra.

O4 Línea de crédito para el financiamiento de emprendimientos turísticos locales.

O5 Emprendimiento local sostenible.

Inventario de atractivos turísticos a potenciar: Déleg cuenta con un inventario de atractivos turísticos bastante extenso, sin

06 embargo, no todos han sido reconocidos aún por el MITUR. Esta es una oportunidad que se genera para poder potenciar estos atractivos.

AMENAZAS 
D1 Carencia de formación sobre el tema de turismo agroalimentario.

D2 Escasa divulgación de los atractivos turísticos del cantón.

Falta de gestión turística a través de un departamento en específico.

No existen comités locales

D4 encargados de controlar la zona alimentaria.

Equipo multidisciplinario para la

D5 formación permanente de los habitantes de la zona.

En la infraestructura: Es escasa la

D6 infraestructura relacionada a hoteles, teatros, cines, sitios para la práctica de deportes, parques y museos.
Pérdida de reservas económicas por el

A1 desconocimiento de los beneficios del turismo en la zona.

A2 Acceso al territorio por la pandemia

A3

Inestabilidad política de los organismos representativos.

A4 Poco conocimiento del desarrollo agro.

A5 Imposición de modelos turísticos

En el aspecto institucional: Insuficiente

A6 apoyo institucional al desarrollo y promoción turística, descoordinación de las instituciones públicas y privadas.

Fuente: Elaboración propia.

Como se puede evidenciar en la Tabla 1, existen factores que influyen directamente en el desarrollo económico del cantón Déleg y que deben ser motivo para impulsar a las regiones y a las instituciones encargadas del crecimiento de la economía a formar espacios donde el turismo a través de los atractivos turísticos, la gastronomía y sus derivados, puedan elevar los niveles y potenciales que esta zona representa, de igual manera, hacer que esas fortalezas sean permanentes y mejoradas en el tiempo, es importante mencionar, que en este cantón existe desconocimiento de los pobladores del potencial agroturístico, por lo que no aprovechan la diversidad y producción agrícola de la zona, unido a la carencia de planes de acción, que inciden directamente en el desarrollo, lo cual constituye centro referencial en esta modalidad.

Tabla 2.

Actores involucrados

\begin{tabular}{ccccc}
\hline $\begin{array}{c}\text { Actores } \\
\text { Involucrados }\end{array}$ & $\begin{array}{c}\text { Interés sobre } \\
\text { problemática }\end{array}$ & $\begin{array}{c}\text { Problemas } \\
\text { percibidos }\end{array}$ & $\begin{array}{c}\text { Recursos y } \\
\text { capacidades }\end{array}$ & $\begin{array}{c}\text { Interés sobre el } \\
\text { proyecto }\end{array}$ \\
\hline $\begin{array}{c}\text { GAD CANTÓN } \\
\text { DÉLEG }\end{array}$ & $\begin{array}{c}\text { Destacar la } \\
\text { importancia del } \\
\text { turismo } \\
\text { agroalimentario. }\end{array}$ & $\begin{array}{c}\text { falta de } \\
\text { recursos para la } \\
\text { promoción } \\
\text { turística del } \\
\text { cantón Déleg. } \\
\text { Escasa }\end{array}$ & $\begin{array}{c}\text { Institución pública } \\
\text { con la capacidad de } \\
\text { lograr } \\
\text { financiamientos. }\end{array}$ & $\begin{array}{c}\text { Promover el } \\
\text { desarrollo } \\
\text { sostenible. }\end{array}$ \\
COMITES & $\begin{array}{c}\text { Realizar } \\
\text { segmentación } \\
\text { de mercados } \\
\text { por los }\end{array}$ & $\begin{array}{c}\text { sobre cómo } \\
\text { desarrollar } \\
\text { proyectos } \\
\text { turísticos. }\end{array}$ & $\begin{array}{c}\text { Conocimiento del } \\
\text { territorio y valores } \\
\text { culturales }\end{array}$ & $\begin{array}{c}\text { Identificar } \\
\text { nuevos actores } \\
\text { para promover } \\
\text { emprendimientos. }\end{array}$ \\
& visitantes. & & \\
& & & &
\end{tabular}


ISSN: 2600-5859

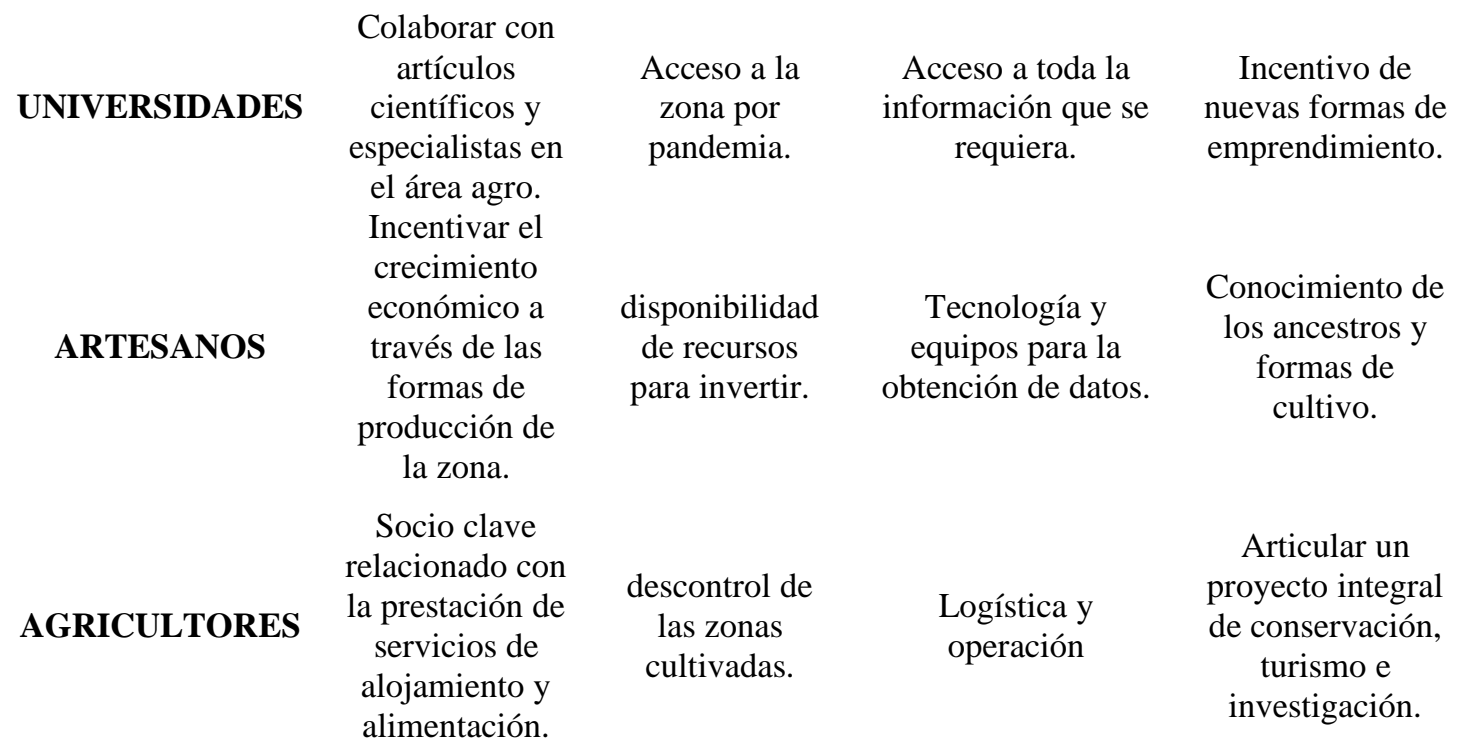

Fuente: Elaboración propia.

En vista a la Tabla 2, se evidencia que si se incrementa el apoyo gubernamental y privado en el sector turístico a nivel parroquial a través de la planeación que logre una definición clara y precisa de objetivos, estrategias y acciones encaminadas al aprovechamiento del potencial agroturístico y la diversidad del cantón Déleg, se podrá revertir el desconocimiento del agroturismo y mejorar las promoción, sensibilización, facilidades e infraestructuras turísticas y por ende contribuir a su desarrollo.

Correspondiendo con el análisis FODA, y para garantizar el funcionamiento eficiente del plan de desarrollo agroturístico que se quiere proponer, se define lo que sería el perfil del cliente según la matriz de Buyer Person en la Tabla 3, donde se describe el posible cliente que puede contribuir al desarrollo del agroturismo en el Cantón Déleg. Según los documentos adjuntos, se puede evidenciar que el cantón Déleg, cuenta con una vocación turística ya que es una región con características especiales que le permiten tener un potencial para el desarrollo turístico, lo que ha permitido la evolución de proyectos para atraer viajeros del Ecuador y de todo el mundo, de igual modo, es posible hacer turismo de aventura, deportivo, gastronómico, arqueológico, ecológico, de diversión, de descanso, religioso, cultural, porque posee un gran potencial turístico, en la modalidad turismo de naturaleza, turismo rural comunitario, turismo ecológico y turismo de aventura.

Con respecto a la pertenencia social se contempla la articulación del Plan Toda una Vida, porque permitirá desarrollar un sistema moderno de gobernanza del turismo, que tenga un esquema jurídico claro, un sistema de información eficiente y un marco institucional fortalecido que facilite el ejercicio de las actividades turísticas en el cantón Déleg, impulsando el proceso de descentralización, con procesos eficientes que contribuyan a la 
sostenibilidad, competitividad y seguridad del sector turístico del cantón, del mismo modo, con el Plan de Desarrollo y Ordenamiento Territorial (PDOT Provincial), porque generará una oferta turística sostenible y competitiva potenciando los recursos humanos, naturales y culturales, junto con la innovación tecnológica aplicada a los componentes de infraestructuras, equipamientos, facilidades y servicios, para garantizar una experiencia turística integral de los visitantes nacionales e internacionales.

De igual forma, se vincula con el Plan de Desarrollo y Ordenamiento Territorial (PDOT Cantonal), porque al posicionar al cantón como un destino turístico sostenible líder que contribuye al logro de los objetivos de desarrollo del milenio con elevada responsabilidad social corporativa y efectiva gestión socio-cultural y ambiental. Así mismo, se relaciona con El PLANDETUR 2020, porque se plantea el reto de orientar la política sectorial con un horizonte al 2021 sobre la base de un acuerdo internacional en el cual la gran mayoría de los Estados del planeta ha reconocido la necesidad de aunar esfuerzos para un desarrollo sostenible y que ahora tiene la oportunidad de sentar las bases para un turismo sostenible en el Ecuador.

El PLANDETUR 2030 busca potenciar en los próximos trece años un desarrollo sostenible integral con visión sectorial para Macroentorno del turismo sostenible en el Ecuador Pertinencia social. Dentro de la pertenencia social en la actualidad las personas están sometidas a demasiadas presiones que les producen tanto desgaste físico como emocional. Así también el ritmo de vida moderno implica deterioro en las relaciones familiares y el tiempo para compartir entre padres e hijos se ha reducido sustancialmente, convirtiendo a los fines de semana como los únicos espacios que pueden ser destinados al turismo y la integración familiar.

Se considera importante vislumbrar el perfil del cliente ideal, es decir cuando se habla de crear el perfil de cliente ideal se habla de generar perfiles ficticios de clientes que encarnan o personifican un tipo específico de comprador de bienes o servicios y así prever el enfoque o visión que ayudará a llegar a él entre otros aspectos; de tal manera que el cantón Déleg pueda dirigir sus esfuerzos y recursos de mejor manera, encaminado a mejorar el desarrollo del turismo en el cantón, en este caso el turista visitante del cantón, para ello, se configura la tabla 3, donde se especifica el cliente ideal que será aquella persona que visite, adquiera productos o servicios del cantón Déleg, porque ha encontrado en él la solución perfecta a su necesidad de hacer turismo de aventura, sano y saludable.

Tabla 3.

Perfil del cliente ideal.

PERFIL DEL CLIENTE IDEAL 
ISSN: 2600-5859

\begin{tabular}{|c|c|c|c|c|c|c|c|c|c|c|}
\hline $\begin{array}{c}\text { Nombre } \\
\text { del Buyer } \\
\text { Person }\end{array}$ & $\begin{array}{l}\text { Información } \\
\text { general }\end{array}$ & $\begin{array}{l}\text { Información } \\
\text { demográfica }\end{array}$ & $\begin{array}{l}\text { Indicadores, } \\
\text { aptitudes } \\
\text { comportamientos }\end{array}$ & $\begin{array}{l}\text { Sueños y } \\
\text { objetivos }\end{array}$ & $\begin{array}{c}\text { Retos y } \\
\text { necesidades }\end{array}$ & $\begin{array}{c}\text { Como } \\
\text { agregamos } \\
\text { valor }\end{array}$ & $\begin{array}{c}\text { Frases o } \\
\text { comentarios }\end{array}$ & $\begin{array}{c}\text { Quejas sobre } \\
\text { productos } \\
\text { similares }\end{array}$ & $\begin{array}{c}\text { Mensaje } \\
\text { de } \\
\text { Marketing }\end{array}$ & $\begin{array}{c}\text { Mensaje } \\
\text { de ventas }\end{array}$ \\
\hline \multirow{3}{*}{$\begin{array}{l}\text { ESQUEDA } \\
\text { ALEXIS }\end{array}$} & $\begin{array}{l}\text { Instructor de } \\
\text { deportes } \\
\text { fitness. }\end{array}$ & $\begin{array}{c}\text { Hombre } \\
\text { Nacionalidad } \\
\text { Argentino }\end{array}$ & $\begin{array}{l}\text { Es defensor del } \\
\text { consumo de } \\
\text { alimentos sano } \\
\text { y nutritivos, } \\
\text { que provengan } \\
\text { de buenas } \\
\text { cosechas. }\end{array}$ & $\begin{array}{c}\text { Crear un } \\
\text { marketin } \\
\text { dedicado a la } \\
\text { promoción del } \\
\text { consumo de } \\
\text { alimentos } \\
\text { sanos. }\end{array}$ & $\begin{array}{c}\text { Trabaja en } \\
\text { Argentina, pero } \\
\text { es fiel visitante } \\
\text { del Ecuador. }\end{array}$ & $\begin{array}{c}\text { Alianzas } \\
\text { estratégicas } \\
\text { con } \\
\text { universidades } \\
\text { que toman la } \\
\text { iniciativa de } \\
\text { promover la } \\
\text { alimentación } \\
\text { sana. }\end{array}$ & $\begin{array}{l}\text { Ecuador } \\
\text { mágica tierra } \\
\text { llena de } \\
\text { energía } \\
\text { infinita. }\end{array}$ & $\begin{array}{c}\text { Es imposible } \\
\text { que las } \\
\text { personas } \\
\text { desconozcan } \\
\text { el poder } \\
\text { curativo de la } \\
\text { naturaleza y } \\
\text { los alimentos. }\end{array}$ & \multirow{3}{*}{$\begin{array}{c}\text { Tu vida } \\
\text { Tu salud }\end{array}$} & \multirow{3}{*}{$\begin{array}{l}\text { Consume y } \\
\text { produce lo } \\
\text { que comes. }\end{array}$} \\
\hline & $\begin{array}{l}\text { Aficionado al } \\
\text { consumo de } \\
\text { alimentos } \\
\text { sanos, } \\
\text { (vegano), y } \\
\text { admirador de } \\
\text { cómo se } \\
\text { cultivan y } \\
\text { cosechan. }\end{array}$ & Edad 42 años & $\begin{array}{c}\text { Le encanta } \\
\text { viajar por sitios } \\
\text { donde se pueda } \\
\text { apreciar el } \\
\text { cultivo de } \\
\text { frutas, } \\
\text { verduras, entre } \\
\text { otros. }\end{array}$ & $\begin{array}{c}\text { Crear una } \\
\text { fundación } \\
\text { dedicada a } \\
\text { ayudar a las } \\
\text { personas que } \\
\text { sufren y } \\
\text { padecen de la } \\
\text { mal nutrición. }\end{array}$ & $\begin{array}{l}\text { Cuenta con el } \\
\text { conocimiento } \\
\text { necesario para } \\
\text { disfrutar } \\
\text { recorridos donde } \\
\text { se muestre la } \\
\text { agricultura del } \\
\text { país. }\end{array}$ & $\begin{array}{c}\text { Convenios } \\
\text { institucionales } \\
\text { para crear } \\
\text { cadenas } \\
\text { comerciales } \\
\text { que } \\
\text { promuevan el } \\
\text { turismo } \\
\text { agroalimentario. }\end{array}$ & $\begin{array}{l}\text { A través de } \\
\text { la naturaleza } \\
\text { sano mi } \\
\text { cuerpo. }\end{array}$ & $\begin{array}{c}\text { Es } \\
\text { preocupante } \\
\text { que a mi edad } \\
\text { no tenga mi } \\
\text { propia red de } \\
\text { marketing. }\end{array}$ & & \\
\hline & $\begin{array}{c}\text { Es especialista } \\
\text { en } \\
\text { investigación } \\
\text { científica y le } \\
\text { llama la } \\
\text { atención el } \\
\text { contacto } \\
\text { directo con la } \\
\text { naturaleza. }\end{array}$ & $\begin{array}{c}\text { Ingreso } \\
\text { promedio: } \\
6.000 \text { dólares }\end{array}$ & $\begin{array}{l}\text { Es fiel creyente } \\
\text { de la energía } \\
\text { que emana la } \\
\text { naturaleza. }\end{array}$ & $\begin{array}{l}\text { Visitar lugares } \\
\text { desconocidos } \\
\text { que estén } \\
\text { puros llenos de } \\
\text { naturaleza } \\
\text { alimentaria. }\end{array}$ & $\begin{array}{c}\text { Piensa que la } \\
\text { alimentación es la } \\
\text { base de la } \\
\text { longevidad en las } \\
\text { personas. }\end{array}$ & $\begin{array}{c}\text { Acercamientos } \\
\text { culturares con } \\
\text { pueblos } \\
\text { indígenas por } \\
\text { medio de la } \\
\text { agricultura. }\end{array}$ & $\begin{array}{l}\text { Ecuador: } \\
\text { misterio del } \\
\text { mundo. }\end{array}$ & $\begin{array}{l}\text { Debo } \\
\text { aprender un } \\
\text { segundo } \\
\text { idioma. }\end{array}$ & & \\
\hline
\end{tabular}

Fuente: Elaboración propia.

En relación al objetivo que corresponde a estructurar los componentes de un plan de desarrollo de agroturismo para el cantón Déleg, se presenta el siguiente esquema:

El plan de desarrollo agroturístico, pretende transformar al cantón Déleg como un importante centro referencial en la práctica del agroturismo debido al inmenso patrimonio natural, cultural y en donde la producción agrícola y ganadera tienen un gran potencial. Por esta razón se han planteado tres objetivos a desarrollar, los cuales se exponen a continuación:

- Fomentar en la población una cultura ambiental y turística.

- Desarrollar y promover el agroturismo.

- Consolidar al turismo sostenible como modelo aplicable para el desarrollo social y económico.

En este sentido, las políticas de Estado para el turismo sostenible del Ecuador, representan las líneas de acción para la gestión interinstitucional y guían la propuesta programática de intervenciones concretas, no obstante, al ser el plan de desarrollo agroturístico para el cantón Déleg una herramienta factible para incrementar los niveles de su economía, se presenta lo siguiente:

Tabla 4.

Estructura plan de desarrollo para el agroturismo.

\begin{tabular}{cccccl}
\multirow{2}{*}{ FASES } & \multirow{2}{*}{ DESCRIPCIÓN } & \multicolumn{2}{c}{ ACTIVIDADES } & $\begin{array}{c}\text { PROGRAMAS } \\
\text { Y/O PROYECTOS }\end{array}$ & \multirow{2}{*}{ RESPONSABLE } \\
\hline FASE I & Esta fase consiste & $\bullet$ Redacción de las & Participación & Investigador
\end{tabular}


ISSN: 2600-5859

\begin{tabular}{|c|c|c|c|c|}
\hline $\begin{array}{l}\text { Formulación } \\
\text { del plan de } \\
\text { desarrollo } \\
\text { agroturístico }\end{array}$ & $\begin{array}{l}\text { en la definición } \\
\text { de las políticas, } \\
\text { estrategias, } \\
\text { programas y } \\
\text { proyectos que se } \\
\text { abordaran en el } \\
\text { plan. }\end{array}$ & $\begin{array}{l}\text { políticas, misión y } \\
\text { visión. } \\
\text { - Determinación de } \\
\text { las estrategias y } \\
\text { objetivo del plan. } \\
\text { - Determinación de } \\
\text { programas } \\
\text { proyectos } \\
\text { propuestos } \\
\text { vinculados } \\
\text { desarrollo agro } \\
\text { turístico. } \\
\text { - Descripción de los } \\
\text { proyectos del plan. } \\
\text { - Presupuesto } \\
\text { estimado y fuentes } \\
\text { de financiamiento } \\
\text { del plan. }\end{array}$ & $\begin{array}{l}\text { ciudadana } \\
\text { - Fomento de la } \\
\text { microempresa. } \\
\text { - Comercialización } \\
\text { de productos } \\
\text { locales } \\
\text { - Liderazgo } \\
\text { comunitario } \\
\text { Capacitación } \\
\text { Turística } \\
\text { - Calidad en el } \\
\text { servicio y atención } \\
\text { al cliente a } \\
\text { prestadores de } \\
\text { servicios. } \\
\text { Plan de marketing } \\
\text { para las } \\
\text { operaciones } \\
\text { agroturísticas. }\end{array}$ & $\begin{array}{l}\text { Comités locales } \\
\text { GAD } \\
\text { MINTUR }\end{array}$ \\
\hline $\begin{array}{c}\text { FASE II } \\
\text { Elaboración } \\
\text { del } \\
\text { cronograma } \\
\text { de ejecución }\end{array}$ & $\begin{array}{l}\text { Esta fase consiste } \\
\text { en el tiempo de } \\
\text { ejecución que } \\
\text { tendrá el plan a } \\
\text { desarrollar. }\end{array}$ & $\begin{array}{l}\text { - Plan de monitoreo y } \\
\text { evaluación del plan } \\
\text { de desarrollo } \\
\text { agroturístico. }\end{array}$ & $\begin{array}{l}\text { Seguimiento y } \\
\text { control del } \\
\text { desarrollo de cada } \\
\text { una de las fases a } \\
\text { realizar. }\end{array}$ & $\begin{array}{l}\text { Comités locales } \\
\text { GAD } \\
\text { MINTUR }\end{array}$ \\
\hline
\end{tabular}

\section{Fuente: Elaboración propia.}

Correspondiendo con los objetivos expuestos, y basándose en las estrategias del plan de desarrollo, se definen dos programas, con un total de 5 proyectos para implementar y desarrollar el agroturismo, los mismos que se exponen en la Tabla 4, donde se evidencian las fases con sus respectivas actividades y programas por los cuales se puede abordar el plan, los programas y proyectos agroturístico que constituyen el eje principal para impulsar y alcanzar el desarrollo sostenible a través de una adecuada planificación estratégica turística cuyo objetivo principal es desarrollar e incrementar la calidad de vida de los habitantes del cantón Déleg. Es importante mencionar, que esta propuesta fue validada por expertos que conocen del tema en estudio.

Con la determinación de los programas y proyectos del plan estratégico y el cronograma de ejecución, se exponen a continuación las proyecciones de los costos de operación y ejecución de los programas con sus respectivos proyectos:

Tabla 5.

Presupuesto estimado.

\begin{tabular}{lccccc}
\multicolumn{1}{c}{ RUBRO } & Año 1 & Año 2 & Año 3 & Año 4 & Año 5 \\
\hline $\begin{array}{l}\text { COSTO DE } \\
\text { OPERACIONES }\end{array}$ & & & & & \\
Materia Prima & $\$ 36.000,00$ & $\$ 37.152,00$ & $\$ 38.340,86$ & $\$ 39.567,77$ & $\$ 40.833,94$ \\
Insumos & $\$ 24.000,00$ & $\$ 24.768,00$ & $\$ 25.560,58$ & $\$ 26.378,51$ & $\$ 27.222,63$ \\
Estudio (Ambiental) & $\$ 0,00$ & $\$ 0,00$ & $\$ 0,00$ & $\$ 0,00$ & $\$ 0,00$
\end{tabular}


ISSN: 2600-5859

Vol. 4, $\mathrm{N}^{\circ} 1.2$, p. 29-53, marzo, 2021

\begin{tabular}{|c|c|c|c|c|c|}
\hline Imprevistos $10 \%$ & $\$ 6.000,00$ & $\$ 6.192,00$ & $\$ 6.390,14$ & $\$ 6.594,63$ & $\$ 6.805,66$ \\
\hline SUBTOTAL & $\$ 66.000,00$ & $\$ 68.112,00$ & $\$ 70.291,58$ & $\$ 72.540,91$ & $\$ 74.862,22$ \\
\hline \multicolumn{6}{|c|}{$\begin{array}{l}\text { COSTOS } \\
\text { ADMINISTRATIVOS }\end{array}$} \\
\hline Sueldos y salarios & $\$ 48.000,00$ & $\$ 52.320,00$ & $\$ 57.028,80$ & $\$ 62.161,39$ & $\$ 67.755,92$ \\
\hline Servicios Básicos & $\$ 0,00$ & $\$ 0,00$ & $\$ 0,00$ & $\$ 0,00$ & $\$ 0,00$ \\
\hline $\begin{array}{l}\text { Útiles de aseo Y } \\
\text { BIOSEGURIDAD }\end{array}$ & $\$ 0,00$ & $\$ 0,00$ & $\$ 0,00$ & $\$ 0,00$ & $\$ 0,00$ \\
\hline Depreciaciones & $\$ 0,00$ & $\$ 0,00$ & $\$ 0,00$ & $\$ 0,00$ & $\$ 0,00$ \\
\hline SUBTOTAL & $\$ 48.000,00$ & $\$ 52.320,00$ & $\$ 57.028,80$ & $\$ 62.161,39$ & $\$ 67.755,92$ \\
\hline \multicolumn{6}{|c|}{ COSTOS FINANCIEROS } \\
\hline SUBTOTAL & $\$ 0,00$ & $\$ 0,00$ & $\$ 0,00$ & $\$ 0,00$ & $\$ 0,00$ \\
\hline \multicolumn{6}{|c|}{ COSTOS DE VENTA } \\
\hline Promoción & $\$ 5.000,00$ & $\$ 5.160,00$ & $\$ 5.325,12$ & $\$ 5.495,52$ & $\$ 5.671,38$ \\
\hline SUBTOTAL & $\$ 5.000,00$ & $\$ 5.160,00$ & $\$ 5.325,12$ & $\$ 5.495,52$ & $\$ 5.671,38$ \\
\hline TOTAL & $\$ 119.000,00$ & $\$ 125.592,00$ & $\$ 132.645,50$ & \$ 140.197,83 & $\$ 148.289,52$ \\
\hline
\end{tabular}

Fuente: Elaboración propia.

El presupuesto proyectado para el plan estratégico de desarrollo agroturístico sería financiado por el Gobierno Autónomo y Descentralizado del cantón Déleg, el GAD parroquial rural de Solano, Ministerios de Ambiente y Turismo, fundaciones especializadas en ayuda a proyectos agroalimentarios como Fundación RUAF, además de contar también con la supervisión y operación técnica de los autores del proyecto, y un equipo de técnicos especializados de la academia en agricultura, turismo y ambiente.

Con la finalidad de obtener elementos respecto a la de validar el contenido del Plan de desarrollo agroturístico en el cantón Déleg, se recogieron opiniones de expertos con práctica laboral y formación enfocada en planificación, promoción turística, procesos de participación ciudadana, investigación, política pública y docencia universitaria, en instituciones como: Ministerio de Turismo, GAD Municipal cantón Cuenca, la academia; con la Universidad del Azuay, Escuela de Turismo; así como el Alcalde del Cantón Déleg.

Los expertos participantes respondieron una matriz en línea conformado por la descripción de las tres fases que contempla el plan, las actividades, sus respectivos programas y proyectos, así como los responsables; que tuvieron que responder si para su criterio se cumple o no se cumplen las fases; junto con observaciones y sugerencias. La matriz se les hizo llegar a través de correo electrónico y en forma física. En definitiva, los expertos opinaron acerca de la Fase 1. Diagnóstico situacional del cantón Déleg. indican que, si cumple en su totalidad, con las observaciones de que posterior al estudio realizado se recomienda al GAD del Cantón 
Déleg realizar un acercamiento con el Ministerio de Turismo para que actualizara y valorara su inventario turístico.

Con respecto a la Fase 2. Formulación del Plan de desarrollo agroturístico También se indica que si cumple y como observaciones se tiene el impulsar los procesos de participación ciudadana en coordinación con el producto Estrella del alcalde.

En relación a la Fase 3. Elaboración del cronograma de ejecución del plan afirman que, si se cumple y como observaciones el entablar anexamente modelos de gestión con participación ciudadana y generar estrategias que vayan ligadas a los planes de ordenamiento territorial.

Desde esta perspectiva, la opinión del alcalde como experto en la validación del plan, afirma que previo a la ejecución del plan de desarrollo agroturístico, el GAD deberá contar con el plan de desarrollo turístico del cantón, mismo que estará articulado al plan de desarrollo y de ordenamiento territorial y en la normativa de la Autoridad Nacional de Turismo. Se recomienda realizar un análisis del entorno es decir describir la situación ambiental, económica, social, política, y patrimonio cultural relevante del cantón enfocando el papel del turismo en cada sector.

En la elaboración de esta fase se deberá considerar los proyectos constantes en el Plan de Trabajo de esta administración mismos que han sido considerados dentro de la actualización del PDOT y al momento se encuentran ejecutando las consultorías respectivas. Se recomienda que dentro de la formulación del plan de desarrollo agroturístico se deberá realizar el respectivo modelo de gestión para la ejecución de los diferentes programas y proyectos que se planteen. Se sugiere considerar la metodología a seguir para realizar el respectivo seguimiento y evaluación del cumplimiento de las metas propuestas en el presente plan de desarrollo agroturístico del cantón Déleg.

De igual forma, el Magister Heriberto López Rodríguez, expone que la información es convincente de la necesidad y expone las potencialidades que aporta el destino y sus necesidades, el producto es la sumatoria de los servicios, no solo son interesantes los atractivos, es necesario realizar inversión como propósito de crecimiento y expansión.

\section{Conclusiones}

A continuación, se exponen las conclusiones y recomendaciones del proyecto para la elaboración de un plan de desarrollo agroturístico. Dichas conclusiones corresponden a los objetivos de estudio del proyecto, los cuales están basados en los aspectos teórico, metodológico y práctico. 
- Referente al diagnóstico de la situación actual del turismo dentro de la perspectiva económica del cantón Déleg, se tiene que cuenta con vocación turística ya que, posee atractivos turísticos como las Ruinas Arqueológicas de Pachamama, Laguna de Guabizhung, Casa Cordero de Surampalti, el templete donde nació Luís Cordero, el Camino del Inca y los centros urbanos de Déleg y Solano, del mismo modo, el cantón Déleg, a través del convenio firmado entre el MINTUR (Ministerio de Turismo) y el GAD Municipal Déleg, se encuentran en plena etapa de implementación de proyectos, como por ejemplo, la señalización ejecutiva de destino, aproximación y colocación de vallas informativas de los principales centros poblados y atractivos turísticos y su parroquia, ruta Religiosa con la colocación de 41 pictogramas con información de igual número de iglesias que se encuentran en esta ruta religiosa con la que cuenta el Cantón.

- Al examinar el FODA, según las encuestas se procedió a utilizar el método analítico donde se identificaron de manera participativa los distintos agentes locales del territorio, las debilidades, amenazas, fortalezas y oportunidades del desarrollo turístico de la zona, se realizó una labor paralela de trabajo donde se determinó un objetivo en común, y es que el cantón Déleg debe lograr consolidarse como un centro referencial importante en la práctica del agroturismo, debido al potencial patrimonio natural - cultural, y sobre todo porque en donde la producción agrícola y ganadera tienen una gran acogida.

- Con respecto a la intervención de los expertos sobre la propuesta de implementación del plan de agroturismo para el cantón Déleg; todos coinciden en que si se cumplen las fases en su totalidad; al existir capacidad práctica para dicha implementación pero al mismo tiempo sugieren que se deben contemplar procesos de participación ciudadana permanente y estrategias ligadas al plan de ordenamiento territorial y los planes de trabajo que mantiene la administración actual de la alcaldía, estos deben ir enlazados para que se puedan ejecutar y alinear, de la misma forma es importante, no solo la presencia de atractivos, es necesario incentivar a realizar inversión como meta de desarrollo y crecimiento turístico.

- Se concluye que, si existe viabilidad técnica para la implementación del plan de agroturismo porque la ejecución y puesta en marcha de la actual propuesta de desarrollo agroturístico busca potencializar las capacidades e iniciativas en el cantón Déleg. Así dentro de la rendición de cuentas 2020 del alcalde del cantón Déleg, se estima que el Gobierno Autónomo Descentralizado del cantón, apunta dentro de sus proyecciones al turismo; con proyectos de inversión referente a planta turística, y primeros estudios de agroturismo, con una inversión destinada de 73.709,44 USD 
más IVA, así se manifiesta, que en el Código Orgánico de Organización Territorial, Autonomía y Descentralización especifica que los Gobiernos autónomos y descentralizados de las parroquias rurales, deben fomentar la inversión y el desarrollo económico.

\section{Recomendaciones}

Una vez presentadas las conclusiones del proyecto, se exponen a continuación las recomendaciones:

- Presentar la actual propuesta a la Junta parroquial, con la finalidad de socializar dicho proyecto para revisar y coordinar su posterior ejecución y desarrollo, con sus correspondientes programas y proyectos para potenciar el desarrollo agroturístico del cantón Déleg.

- Gestionar fuentes de financiamiento, para implementar los programas y proyectos propuestos en esta investigación con el propósito de potenciar el desarrollo turístico del cantón.

- Incrementar el apoyo gubernamental al sector turístico, al, a través de una adecuada planificación que logre una definición clara y precisa de objetivos, estrategias y acciones encaminadas al aprovechamiento del potencial agroturístico y la diversidad para revertir el desconocimiento del agroturismo y mejorar la promoción, sensibilización, facilidades e infraestructuras turísticas y contribuir al desarrollo sostenible.

- Por otro lado, el producto turístico considerado como una sumatoria de los diferentes servicios que se ofertan; no sólo son interesantes los atractivos, puede ser muy valiosos al significar la inversión como propósito de crecimiento y expansión. Pretendiendo funcionar conjuntamente.

- Crear un organismo local que apoye y administre la actividad turística y comunitaria, para que se proyecte un proceso de participación paulatina de la comunidad con el fin de que ellos sean los encargados de la gestión del agroturismo.

- Coordinar con los GADS de las ciudades de Cuenca, Azogues y otros cantones de la región para realizar promoción turística intensiva como sitios de recreación para fines de semana para partiendo de ello consolidarse como destino turístico complementario.

\section{Referencias bibliográficas.}

Abreu, J. (2014). El Método de la Investigación Research Method. Daena: International Journal of Good Conscience., 195-204. 
Alonso, G. (2019). El Agroturismo, una visión desde el desarrollo sostenible. Revista Centro Agrícola, 46(1), 62-65.

Anago, A., \& Rodriguez, B. (2013). Propuesta de desarrollo turistico comunitario en la parroquia de Mindo. Quito: Universidad Central del Ecuador.

Arrieta, D. (2006). El Turismo rural en Costa Rica, una visión agroecoturística. TECNITUR, 1(3), 77.

Barrera, E. (2009). Las Rutas alimentarias como instrumento para el desarrollo territorial: el caso de la Ruta de la Yerba Mate de Argentina. Revista de la Universidad de Sonora, $19-22$.

CFN. (2017). Sector Turístico - Nivel Nacional. Quito: Corporación Financiera Nacional.

Chryssoula et al. (2009). Examinando la relación entre las emociones, la satisfacción del cliente y las futuras intenciones de comportamiento en el agroturismo. Turismo, 4(4), $145-161$.

GAD Déleg. (25 de 5 de 2020). GAD Déleg Municipal. Obtenido de http://www.gadmunicipaldeleg.gob.ec/gadmunicipaldeleg/

Gambarota, D., \& Lorda, M. (2017). El turismo como estrategia de desarrollo local. Revista Geográfica Venezolana, 58(2), 346-359.

Jaimes, E., \& al, e. (2016). Análisis de la calidad de vida en el Cantón Déleg, Provincia del Cañar-Ecuador. Revista Venezolana de Gerencia, 21(75), 460-488.

Ministerio de Turismo. (25 de 5 de 2020). Ministerio de Turismo Ecuador. Obtenido de https://www.turismo.gob.ec/agroturismo-estrategia-que-se-trabaja-con-los-actoresde-la-industria-turistica-nacional/

Mora, A. (2011). Perspectivas Filosóficas Del Hombre (Tercera ed.). San José: EUNED.

Muñoz, J., \& Requena, K. (2006). Turismo e Internet. Factores de desarrollo en países subdesarrollados. Revista Actualidad Contable, 9(12), 118-131.

OMT. (25 de 5 de 2020). Organización Mundial del Turismo. Obtenido de GLOSARIO DE TÉRMINOS: https://www.unwto.org/es/glosario-terminos-turisticos

Roig, J. (14 de 8 de 2014). Revista América Económica. Obtenido de Revista América Económica: https://mba.americaeconomia.com/articulos/reportajes/turismo-ruralcomo-america-latina-puede-sacar-mas-provecho 
Velasco, A., \& Cerro, A. (2014). Aproximación al concepto de agroturismo a través del análisis de la legislación española en materia de agroturismo. Badajoz: Universidad de Extremadura.

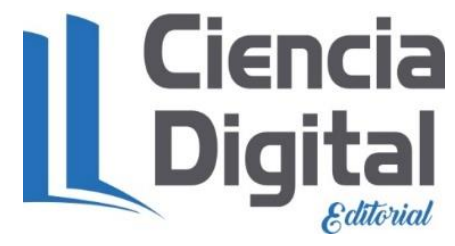


PARA CITAR EL ARTÍCULO INDEXADO.

Castillo Ortega, Y., Cobos Izquierdo, N. C., \& Covri Rivera, D. (2021). El agroturismo como estrategia de dinamización económica local para el Cantón Déleg. ConcienciaDigital, 4(1.2), 29-53. https://doi.org/10.33262/concienciadigital.v4i1.2.1579

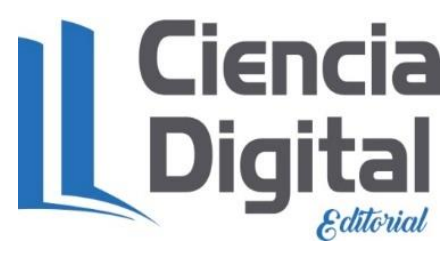

El artículo que se publica es de exclusiva responsabilidad de los autores y no necesariamente reflejan el pensamiento de la Revista Conciencia Digital.

El artículo queda en propiedad de la revista y, por tanto, su publicación parcial y/o total en otro medio tiene que ser autorizado por el director de la Revista Conciencia Digital.
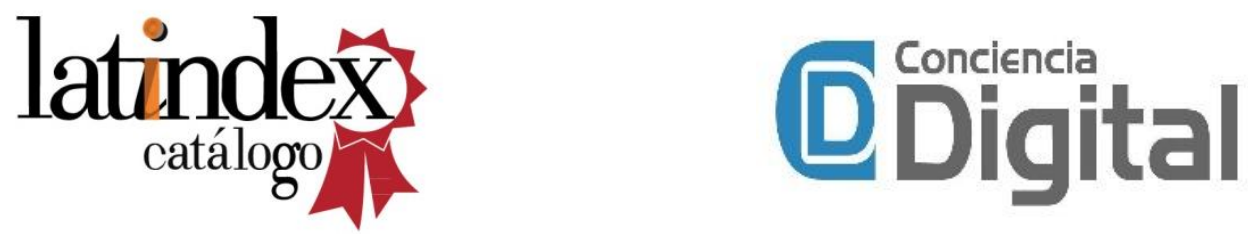